\title{
Stabilizing Burden Trajectory into Blast Furnace Top under High Ore to Coke Ratio Operation
}

\author{
Yoshiyuki MATSUI, Akito KASAI, Kenji ITO, ") Tadasu MATSUO, (1) Shuji KITAYAMA, ${ }^{11}$ \\ and Nobuyuki NAGA ${ }^{21}$ \\ R \& D Lab., Kobe Steel, Ltd., Ikeda, Onoe-cho, Kakogawa, Hyogo 675-0023 Japan. \\ 1) Kobe Works, Kobe Steel, Ltd., Nadahama-higashimachi, Nada-ku, Kobe, Hyogo 657-0863 Japan. \\ 2) Measurement \& Control Gr., System Engineering Dept., Shinko Mex Co. Ltd., Kanazawa-cho, Kakogawa, Hyogo $675-0137$ \\ Japan.
}

(Received on December 11, 2002; accepted in final form on March 11, 2003)

\begin{abstract}
It becomes still more important to control the falling trajectory in order to stabilize burden distribution control under intensive coal injection in a blast furnace. The present report clarifies the effect of ore falling trajectory on coke collapse in a two-dimensional bell-less burden distribution test and the effect of burden particle size on the falling trajectory, which serves as a disturbance factor. There has been no analysis on the motion on a bell-less rotating chute and falling parabolic motion as a mass flow, and particle dynamics are applied, and it is presently difficult to predict changes of the falling trajectory as a mass flow. Therefore, a falling trajectory measuring technique was developed utilizing acceleration sensors that can continuously measure the falling trajectory of burdens, in particular, the main stream position and the falling width, and was actually applied to Kobe BF3 (3rd campaign) (inner volume: $1845 \mathrm{~m}^{3}$; blown in on April 5, 1983). It has been confirmed that this falling trajectory measuring technique has enabled the measurement of the falling trajectory which is subject to centrifugal force on the rotating chute, a discharge flow rate from a top hopper, and particle size segregation, and which varies in time series, and furthermore, the physical main stream position that is determined by the mass flow rate can be determined uniquely.
\end{abstract}

KEY WORDS: blast furnace; burden distribution control; falling trajectory; pulverized coal injection; bell-less charging; coke collapse; pellets.

\section{Introduction}

For means to control radial distribution of blast-furnace top burdens, there are movable armors which have been developed with an increase of the furnace size as well as tilting angle control of bell-less top charging equipment, in addition to conventional stock level height, charging sequence, coke base change, etc., and Sakurai ${ }^{1)}$ summarized these controls. In these distribution controls, all are based on where ore or coke should be dropped or how they should be dropped. Falling trajectories are formulated by dynamically expressing the course of materials how they are discharged from charging equipment and reach the burden surface in the furnace, but with respect to the motion on the lower bell surface or distributing chute as well as falling parabolic motion, no analysis has been available as a mass flow and the particle dynamics are applied. ${ }^{2}$

As against the case of bell armors in which materials are discharged along the lower bell surface and the jump-out angle is equal to the lower bell angle, in the bell-less top charging, materials have velocity distributions not only in the chute longitudinal direction at the chute tip end but also in the tangential direction of the chute surface, and since they come out from the rotating field at this place, components of the size and the direction same as those of chute rotating speed are imparted. Furthermore, since in the case of bell-less top charging, the material discharge speed is about $1 / 10$ that of bell armors and long discharging time is required, the materials are subject to discharge flux from the top hopper and particle segregation in the hopper, and the width of falling stream is several times wider than that of bell armors. However, in the case of bell-less top charging, there are a few examples of actual measurement using full-scale models, but there are scarcely measurement cases in actual furnace. ${ }^{3,4)}$

In this paper, discussion will be made on the importance of falling trajectory control in achieving stability of burden distribution control under high ore to coke ratio operation with the intensive coal injection in bell-less top charging, development of falling trajectory measuring technique that enables the control, and the results of applying the technique to actual furnace from the viewpoint of relation between changes of various phenomena of burden distribution formation and its controllability, and it is our sincere hope that the paper would contribute to further improvement of operational flexibility. 

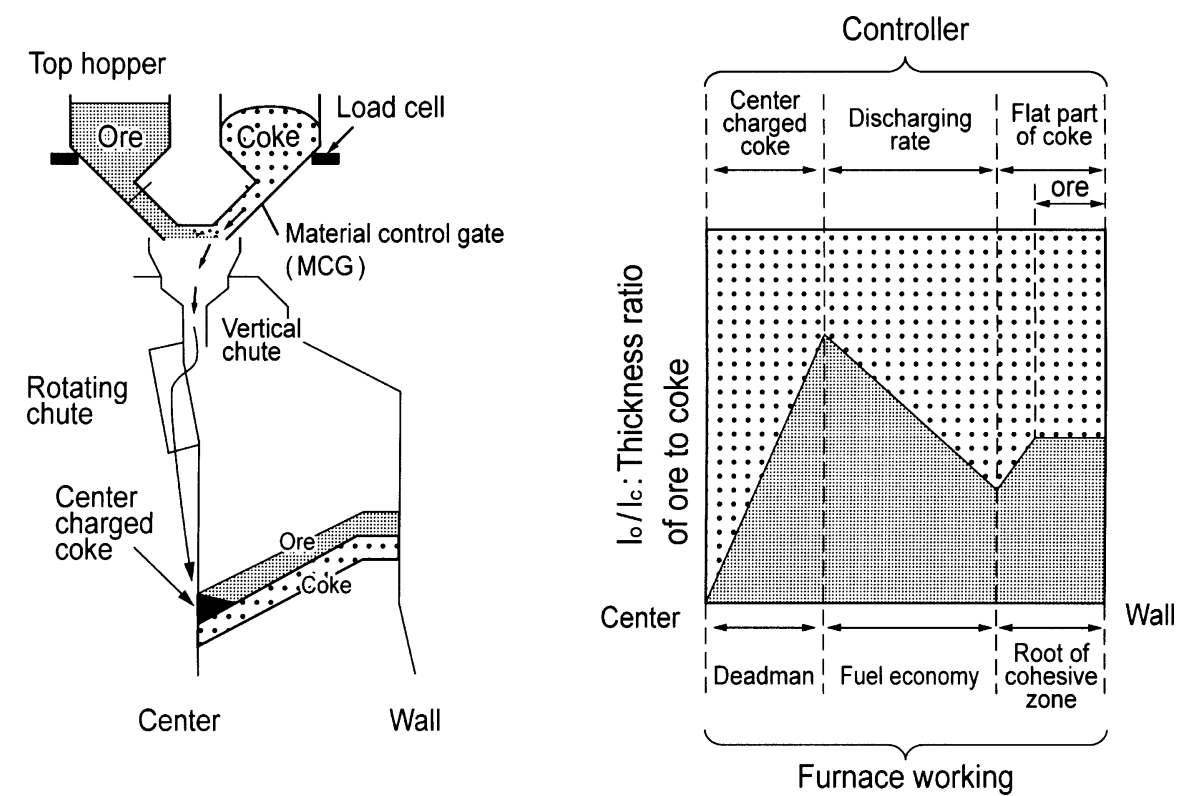

Fig. 1. Burden distribution control on Kobe Works.

\section{Effects of Falling Trajectory on Burden Distribution Control}

Figure 1 shows the basic concept and the method of burden distribution control that meets operation under intensive coal injection. Under high $\mathrm{O} / \mathrm{C}$ operation associated with an increase of pulverized coal ratio, it is essential to control coke layer collapse and formation of mixed layer, ${ }^{5-7)}$ and properly maintain the gas flow inside the furnace. In Kobe Steel's bell-less system shown in left figure, flat parts are formed for both ore and coke in the peripheral region to suppress layer collapse, and the thickness ratio of ore to coke shown in right figure is smoothed on peripheral regions, and by coke center charging, ${ }^{8)}$ the inversed-V cohesive zone is intended to be formed. In order to accurately control the flat part length, it is essential to quantitatively assess the degree of influence of ore falling trajectory on coke layer collapse, and find out the sensitivity of falling trajectory to particle size fluctuation of burdens, which is a main disturbance factor, in other words, buffer capacity.

Figure 2 shows a two-dimensional bell-less burden distribution test apparatus, which is a 1/7.4 model of Kobe BF3. For materials, coke and sintered ore whose mean particle size was adjusted to the scale ratio same as that of the apparatus were used.

Figure 3 shows the effect of coke flat part length on coke layer collapsing rate with distance $(r)$ from inner edge of coke flat part in case of setting same tilting angle of ore and coke. When ore is charged and superimposed on the coke layer surface, the coke surface layer part collapses as it is subject to the loading force. ${ }^{5-7)}$ Little coke layer collapse occurs by charges up to the second rotation, but by charges of the third rotation, the coke layer is greatly scraped, and the collapsing rate increases as the coke flat part increases. This is because when the ore falling angle $(\theta)$ is reduced, the ore falling trajectory approaches closer to perpendicularity, and the ore falling impact force increases.

For measures against the rise of $\mathrm{O} / \mathrm{C}$ as a result of increase of pulverized coal rate and furthermore, accelerated

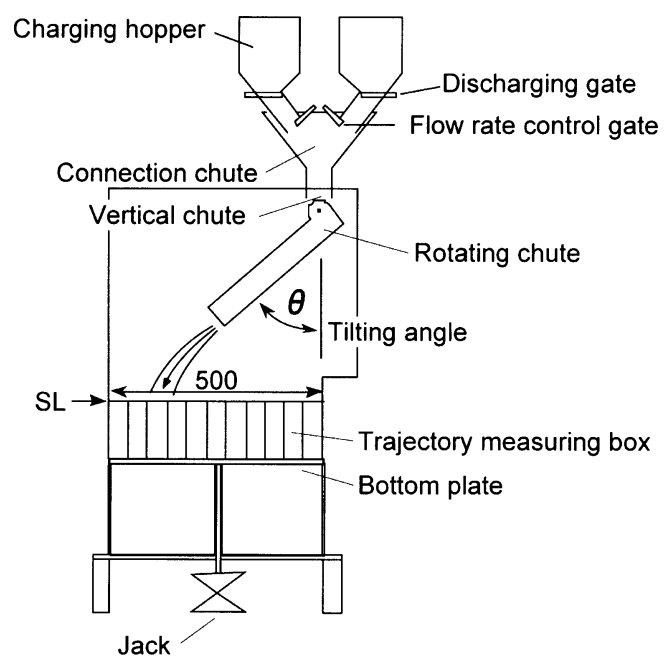

Fig. 2. Schematic diagram of 2-dimensional model (1/7 model of Kobe No. 3 BF).

low-fuel rate, a means of increasing ore base in the cokebase operation, a means of lowering the coke base in orebase operation, and combination of both means are selected.

Figure 4 shows the effect of ore charging angle on coke layer collapse rate when coke flat part length is constant. As the ore charging angle is decreased, the coke layer collapse rate increases. Consequently, when flat parts are formed for both ore and coke and the ore base rate is increased to cope with the rise of $\mathrm{O} / \mathrm{C}$, the control of ore falling trajectory gains in further more importance.

Figure 5 shows the effect of coke charging flux on coke falling flow rate distribution in the furnace throat radial direction. The falling flow rate distribution was indicated by installing a collection box partitioned in the radial direction at the furnace throat section and obtaining weighted mean of the accumulation height at each division. When the coke burden flux is decreased by decreasing the flow control gate opening, the main falling stream position is deviated to the furnace wall side. This means that the coke flat part is de- 

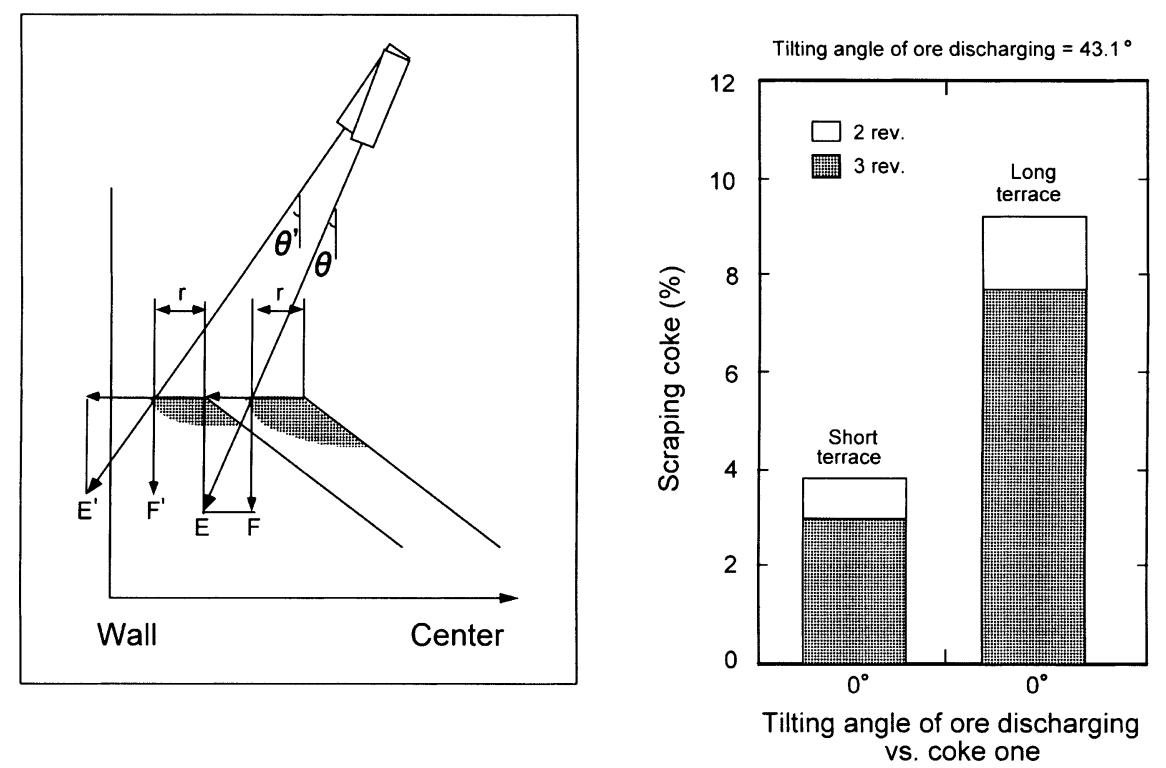

Fig. 3. Effect of coke flat part length on scraping coke.
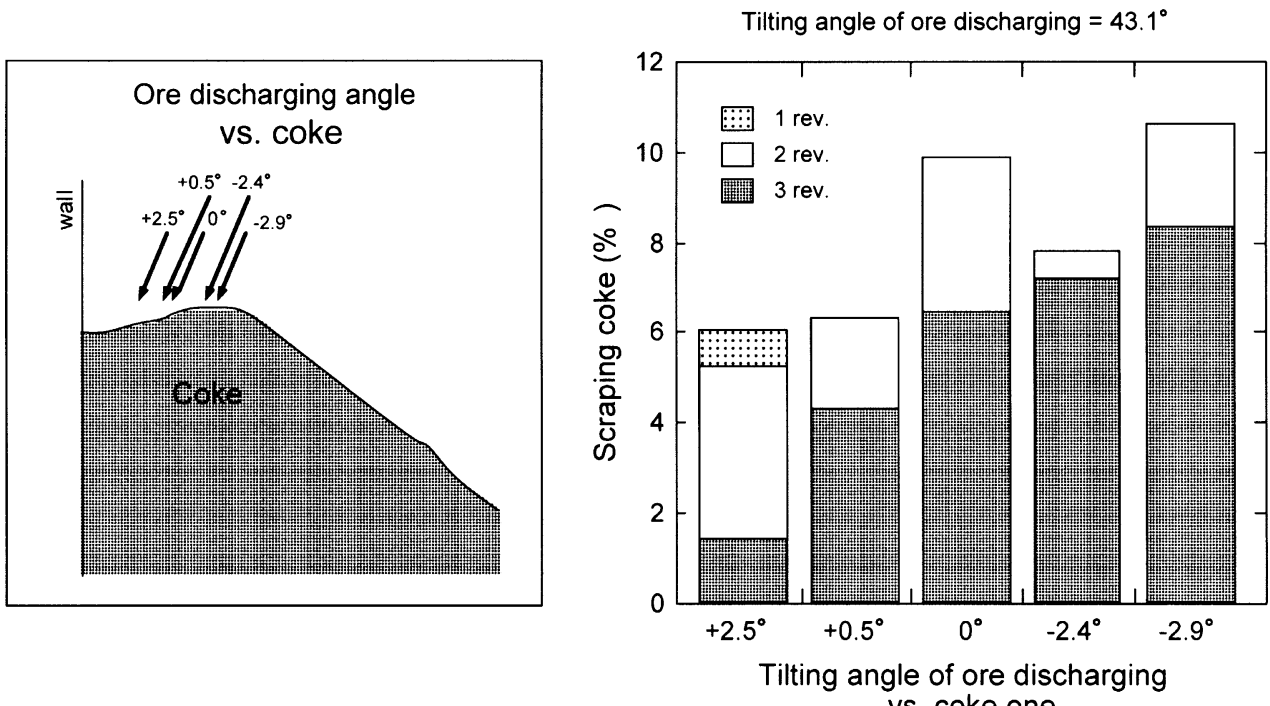

Fig. 4. Effect of ore hitting position on scraping coke.

Sinter : $1-3 \mathrm{~mm}$, Tilting angle : $40.7^{\circ}$

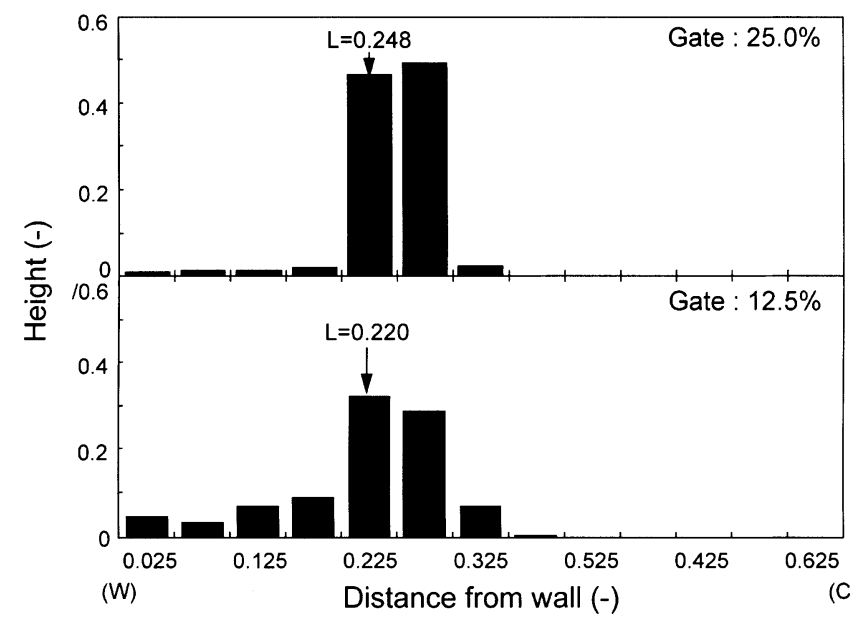

Fig. 5. Effect of coke charging amount on falling point from side wall. creased even in the same bell-less point charging. In addition, when the flow control gate opening is narrowed, the coke falling flow rate distribution expands. This is because frictional resistance of coke particles in the falling stream lowers as the flux decreases, and the effect of repulsion on the rotating chute when coke particles fall from vertical chute to rotating chute increases. Consequently, when the coke base is lowered for the rise of $\mathrm{O} / \mathrm{C}$, it becomes clear that importance of control of coke falling trajectory still more increases.

The foregoing description suggests that for the rise of $\mathrm{O} / \mathrm{C}$, in the coke-base operation, control of the ore falling trajectory and in the ore-base operation, control of coke falling trajectory gain in greater importance.

Figure 6 shows the effect of material particle size in the relation of falling main stream positions of ore and coke to the tilting angle of rotating chute. As the tilting angle of rotating chute decreases, the falling main stream position can be shifted to the furnace inner side, but on the other hand, 
as particle size decreases for both ore and coke, the falling main stream position is shifted to the furnace inner side. This is because frictional resistance increases between particles in the falling stream as the particle size decreases, and the jump-out speed of particles from rotating chute lowers. Furthermore, apparent effects of particle size on falling main stream position are indicated as the tilting angle is lowered. This is because an increase of frictional resistance is more conspicuously manifested between particles in the falling stream accompanied by decreased particle size as repulsion, and frictional resistance on the rotating chute decreases with a decrease of particle size.

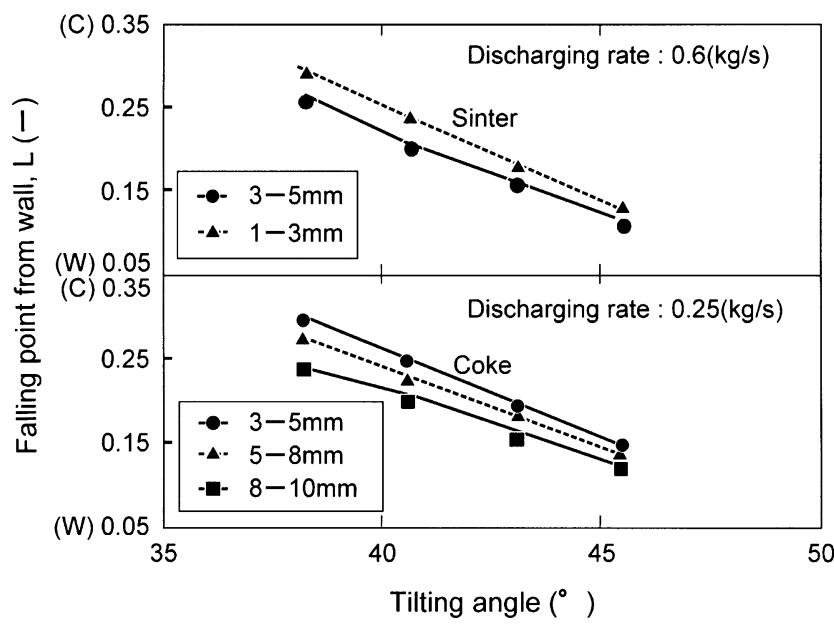

Fig. 6. Effect of tilting angle of distributing chute on falling point from side wall.
Consequently, lowering the tilting angle of rotating chute for forming flat parts for both ore and coke as a result of shifting to higher $\mathrm{O} / \mathrm{C}$ operation increases the effect of burden particle size on the falling trajectory, which serves as the disturbance factor, and unstable control of falling trajectory will result.

Based on the foregoing description, the effect of shifting to high $\mathrm{O} / \mathrm{C}$ operation on changes of falling trajectory and burden distribution control can be summarized as described in Table 1.

\section{Development of Falling Trajectory Measuring Technique and Application to Actual Furnace}

\subsection{Development of Falling Trajectory Measuring Technique}

As described above, there has been no analysis as massflow on the motion and falling parabolic motion on the distributing chute, and particle dynamics are applied, and it is presently difficult to predict changes of falling trajectory as mass flow which has been verified in a two-dimensional bell-less burden distribution test. Therefore, recently, a falling trajectory measuring technique utilizing acceleration sensors which can continuously measure the burden falling trajectory, particularly, the main stream position and falling width, has been developed.

Figure 7 shows general structure of compression type piezoelectric acceleration sensor whose stress direction is longitudinal. The piezoelectric type acceleration sensor operates on a measuring principle in that the element finds the

Table 1. Importance of burden trajectory on intensive coal injection.

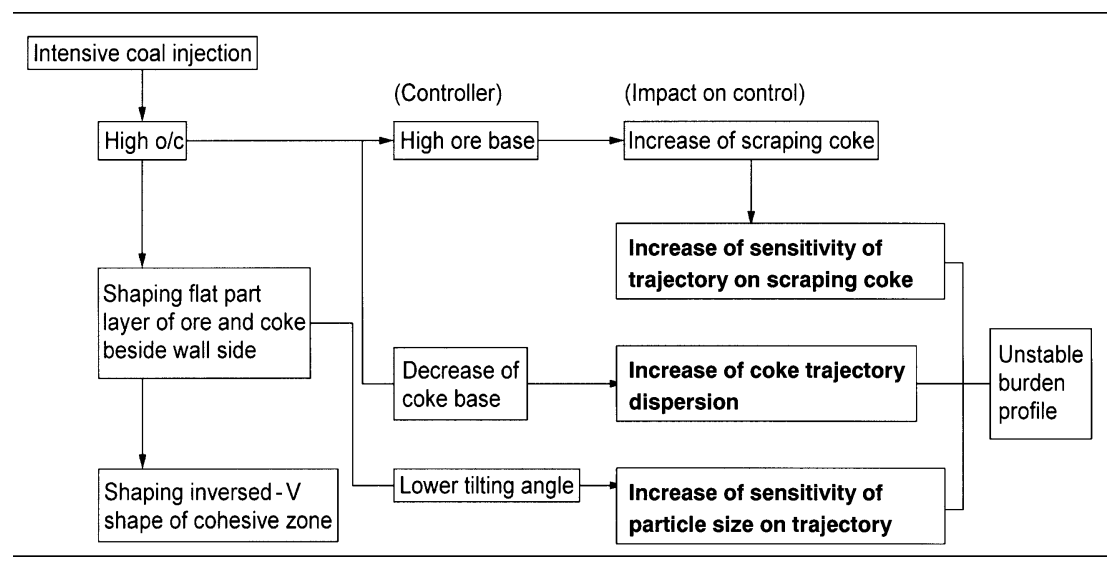

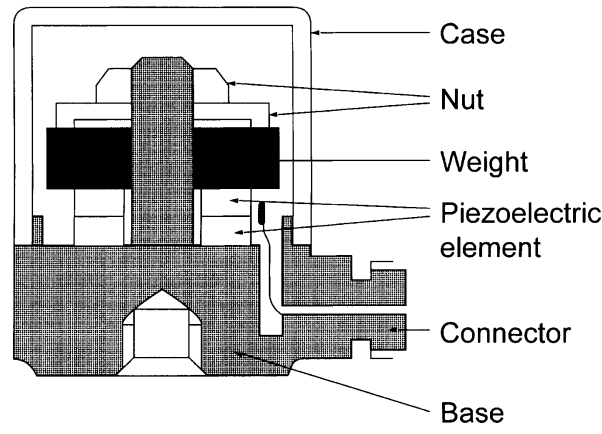

Fig. 7. Structure of acceleration sensor of pressure transform type.

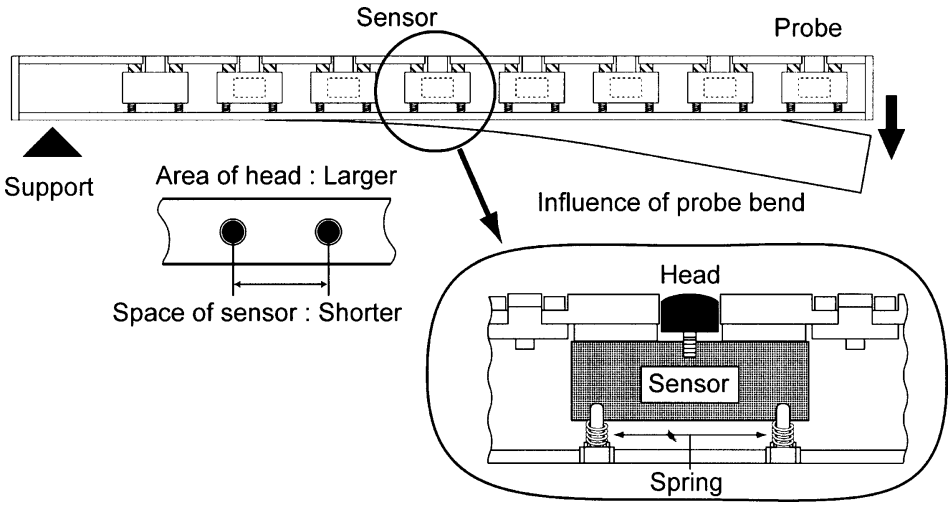

Fig. 8. Structure of burden trajectory probe. 
acceleration by detecting electric charge generated when force is applied to piezoelectric element.9)

Figure 8 shows a cross section and an enlarged view of falling trajectory measuring probe with acceleration sensors installed at specified intervals. To achieve higher measuring accuracy, the sensor intervals were narrowed to $10 \mathrm{~mm}$ and the area of sensor head section was set as big as possible. Furthermore, it is characterized in that sensors are fixed indirectly via buffer material for eliminating propagation of material colliding force to sensors through probe proper.

Figure 9 shows acceleration signals in single ball drop tests when kind of dropping samples and drop height were varied. Sensors detect sharp downward acceleration signals with short frequency right after the sample is dropped, which thereafter are attenuated. With respect to waveform of acceleration signals, when the drop height is constant, the greater the sample weight, or when the sample weight is constant, the greater the drop height, the greater is the maximum value of acceleration signal.

Figure 10 shows outputs of acceleration signals in drop tests of a plurality of balls, which were carried out to assess the falling trajectory when drop specimens are mass flow. The test shows when $10 \mathrm{~kg}$ of pellets were dropped on the 4 th sensor right above the probe. The No. 3 to No. 5 sensors against which samples collided detect acceleration signals in short cycles and high amplitudes. The standard deviation of this acceleration signal is calculated and the results are shown on the right figure of Fig. 10. The standard deviation distribution indicates the strength distribution of dropping position and it can be judged that the maximum value of approximated curve of standard deviation distribution is the main stream position of mass flow which can be physically defined.

\subsection{Application of the Falling Trajectory Measuring Technique to an Actual Furnace}

Based on the foregoing basic test results, the falling trajectory measuring technique was applied to Kobe BF3 (3rd campaign) (inner volume: $1845 \mathrm{~m}^{3}$; blown in on April 5, 1983), and the test was begun on blast-furnace major maintenance days from June 12, 1998, and application of the technique to the actual operation was started on April 7, 1999. Figure 11 outlines the falling trajectory measuring system. A probe with sensors incorporated is of a doublepipe construction and is fixed in such a manner that the probe is exposed to the top surface of the outer pipe. Because the probe is charged into the furnace by the travel of cableveyor, measurement during operation is possible.

Figure 12 shows the distribution of the standard deviation of acceleration signals when coke is charged by 9 rotations at the same bell-less point. By the way, for verifying the measurement accuracy of falling trajectory, the probe top surface was colored with paint and the collision position was verified from peeling of the paint at the time of coke collision. The standard deviation distribution of acceleration signals is shifted to the wall side as coke is subject to the centrifugal force on the rotating chute. Consequently, the center position of the strong striking points assumed from peeling of paint does not coincide with the main stream position detected from the standard deviation distribution of acceleration signals. Consequently, it has been

\begin{tabular}{|c|c|c|}
\hline Sample & $\begin{array}{c}\text { Weight } \\
\text { (g) }\end{array}$ & \begin{tabular}{|c} 
Height \\
$(\mathrm{m})$
\end{tabular} \\
\hline $\begin{array}{c}\text { Alumina } \\
\text { ball }\end{array}$ & 2.0 & 1.0 \\
\hline $\begin{array}{c}\text { Glass } \\
\text { ball }\end{array}$ & 1.5 & \multirow{4}{*}{2.0} \\
\hline $\begin{array}{c}\text { Alumina } \\
\text { ball }\end{array}$ & 2.0 & \\
\hline $\begin{array}{l}\text { Iron ore } \\
\text { pellet }\end{array}$ & 4.9 & \\
\hline $\begin{array}{l}\text { Steal } \\
\text { ball }\end{array}$ & 5.4 & \\
\hline
\end{tabular}

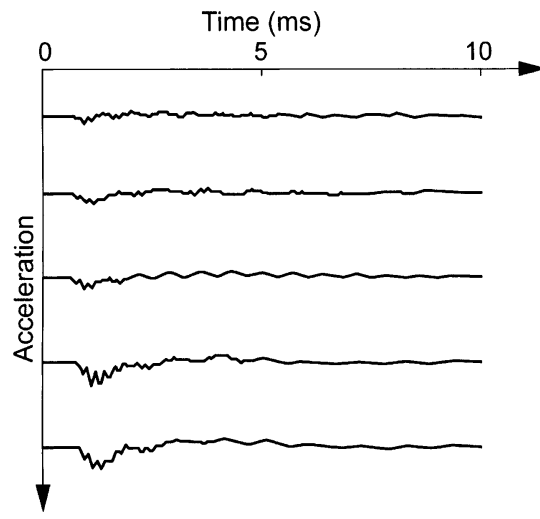

Fig. 9. Effect of charging condition on acceleration signal.
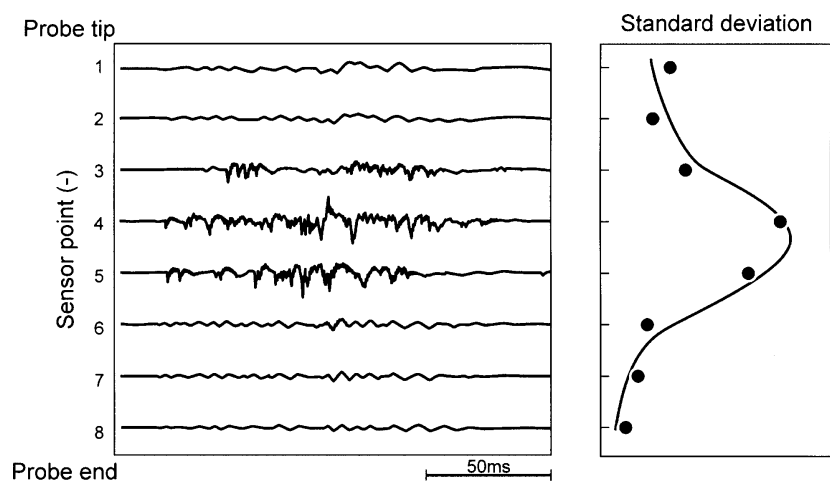

Fig. 10. Longitudinal distribution of acceleration signal and intensity of burden trajectory.

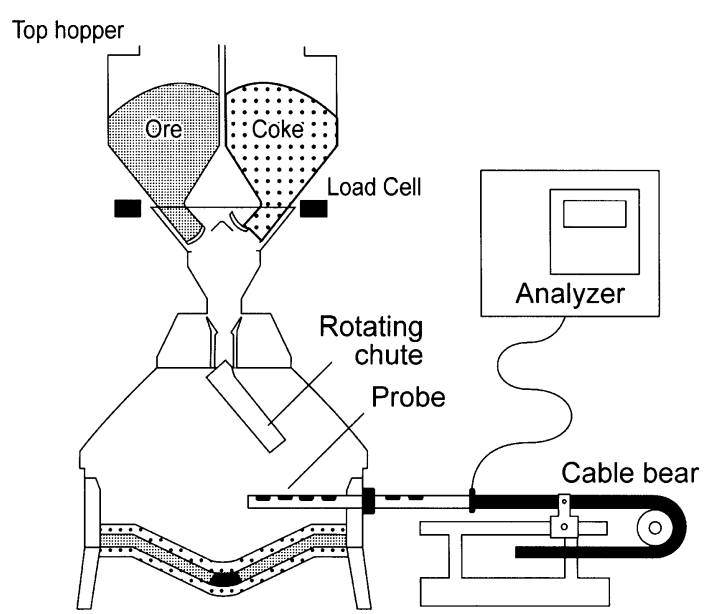

Fig. 11. Diagram of burden trajectory probe at Kobe No. 3 blast furnace.

confirmed that the physical main stream position determined by mass distribution by the effect of centrifugal force on the rotating chute can be uniquely determined by the present falling trajectory measurement.

Figure 13 shows the standard deviation distribution of acceleration signals when the bell-less point defined by the vertical angle of rotating chute was changed and sintered ore was charged by 6 rotations. It has been able to be confirmed that the standard deviation distribution of acceleration signals can follow changes of bell-less point. Furthermore, what is interesting is that the standard devia- 
tion distribution of acceleration signals is varied even at the same bell-less point. This is because the falling stream is subject to discharge flux from the top hopper and particle size segregation in the hopper and the falling stream is var-

(a) Intensity distribution on trajectory probe by burden collision

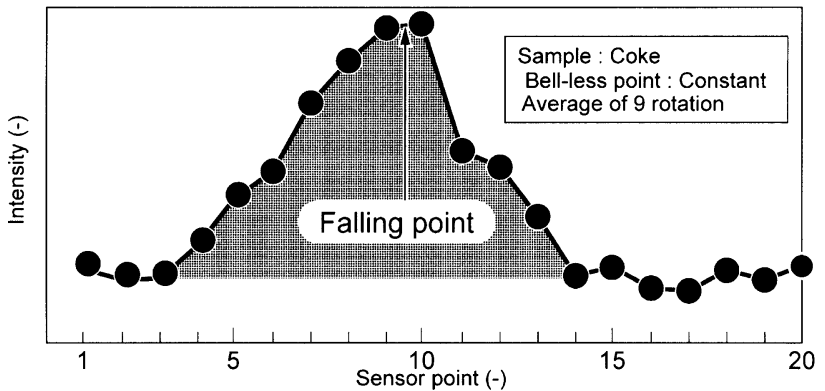

(b) Collision detection by paiting bar

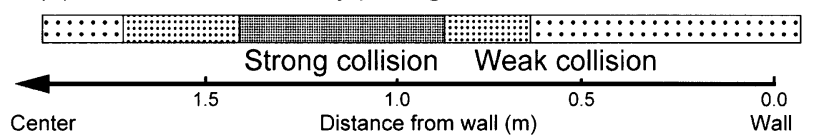

Fig. 12. Comparison of burden trajectory distribution. ied in time series as the discharge time is long in the case of bell-less charging as described above.

\section{Improved Controllability of Blast Furnace by Falling Trajectory Measurement Technique}

In Kobe BF3 (3rd campaign), pretreated ore was totally changed over to externally supplied one and the use of pellets was begun as a result of shutdown of a sintering plant in the end of May 1999, and all-pellet operation (73\% pellet and $27 \%$ lumpy ore) was begun in the end of September 2001. ${ }^{10)}$ Because pellets have a small friction coefficient with the chute wall surface, they are swung upwards in the rotating chute. ${ }^{11)}$ Because from the viewpoint of circumferential balance, promoted discharge deflection due to discharge characteristics of parallel two-stage furnace top hopper was feared by the swing-up of pellets inside the rotating chute, monitoring of the ore falling trajectory was encouraged.

Figure 14 shows the effect of increased pellet ratio on the main stream position of ore falling from the rotating chute at the point in the outermost ring, which is generally

\begin{tabular}{|c|c|}
\hline $\begin{array}{c}\text { Rotating } \\
\text { number }\end{array}$ & $\begin{array}{c}\text { Bell-less } \\
\text { point }\end{array}$ \\
\cline { 1 - 1 } 1 & \multirow{2}{*}{ A } \\
\cline { 1 - 1 } 2 & \multirow{2}{*}{ B } \\
\cline { 1 - 1 } 4 & \\
\cline { 1 - 1 } 5 & \multirow{2}{*}{ C } \\
\cline { 1 - 1 } 6 & \\
\hline
\end{tabular}

Fig. 13. Change of sinter trajectory distribution by bell-less point.

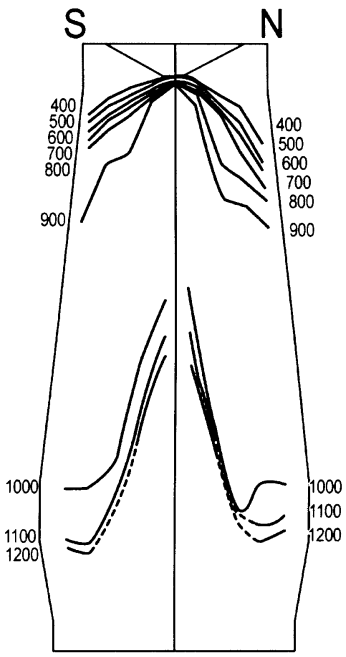

(a)Pellets ratio of $0 \%$

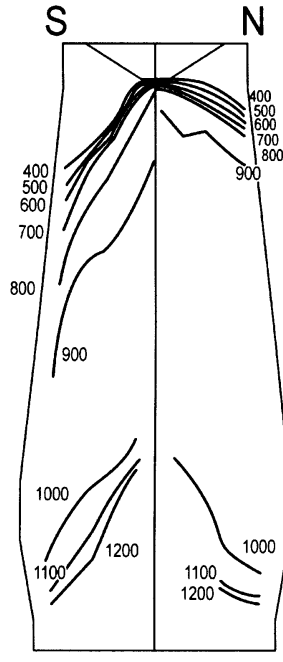

(b) Pellets ratio of $26 \%$

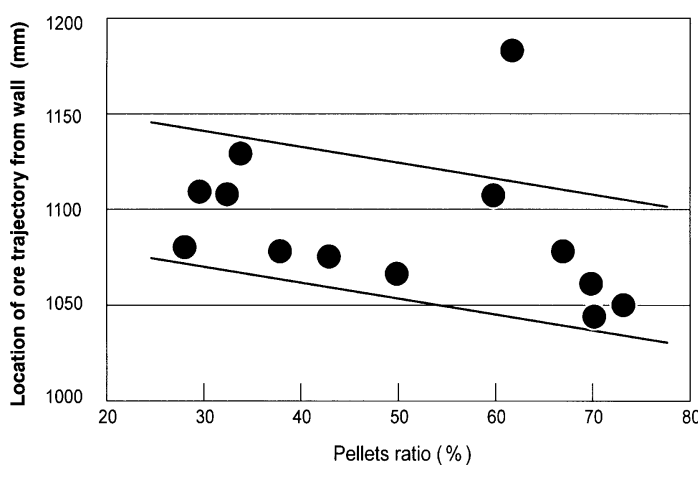

Fig. 14. Effects of pellets ratio on ore trajectory fallen from rotating chute.

(Units : $\left.{ }^{\circ} \mathrm{C}\right)$

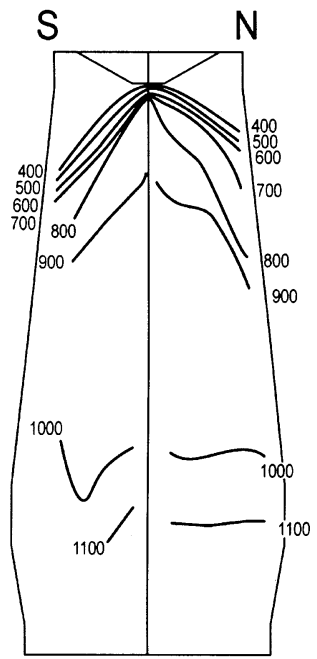

(c)Pellets ratio of $43 \%$

Fig. 15. Changes of temperature distribution in furnace by increasing pellets ratio. 


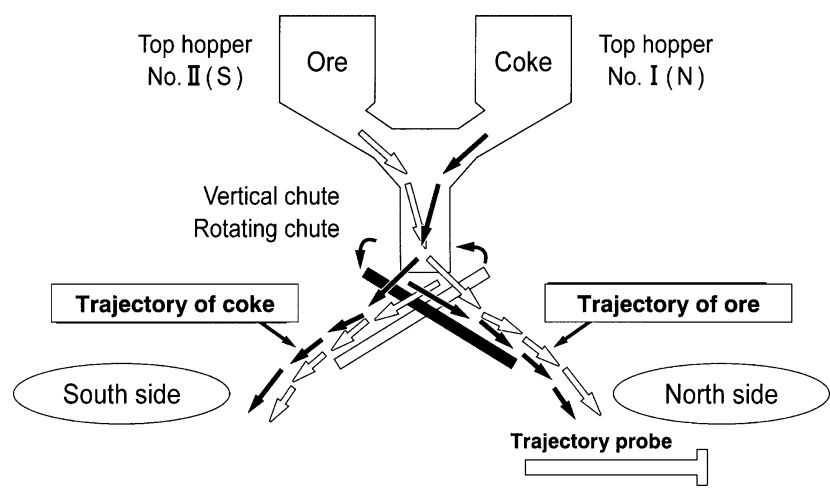

Fig. 16. Circumferential balance of trajectory fallen from rotating chute.

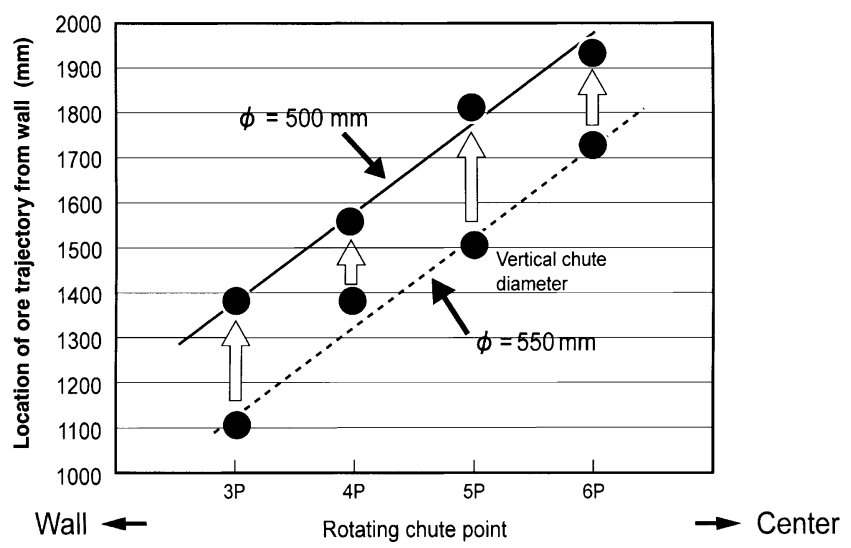

Fig. 17. Effects of reducing vertical chute diameter on ore trajectory.

used. The bell-less point was shifted to the furnace wall side because the ore falling trajectory was swung up in the rotating chute as the pellet ratio was increased.

Figure 15 shows changes of in-furnace temperature distribution associated with increased pellet ratio. At $26 \%$ pellet, the south-north balance of in-furnace temperature distribution was lost (Fig. 15(b)). This is attributed to the promoted discharge deflection of coke and ore in south to north caused by the swing-up in the rotating chute as a result of increased pellet ratio in the discharge characteristics of parallel two-stage furnace top hopper as shown in Fig. 16. To cope with this, the inside diameter of vertical chute was reduced from 550 to $500 \mathrm{~mm}$. Figure 17 shows changes of ore falling trajectory before and after reducing the vertical chute diameter. The ore falling trajectory was corrected to the furnace inner side by preventing from ore swing up by increasing the friction in vertical chute and as a result, the south-north balance of in-furnace temperature distribution was corrected (Fig. 15(c)).

Consequently, the application of the falling trajectory measuring technique to the actual furnace has made it possible to apply the falling trajectory measuring technique to the detection of circumferential balance of material charging from the furnace top by assessing the falling trajectory, which varies in time series under the influence of bell-less point, discharge flux from furnace-top hopper, and particle size segregation.

In the blast furnace burden distribution control, the circumferential distribution is important in addition to radial distribution, and if there is even one unfavorable part in the circumferential direction, it becomes rate-controlling, and the operation must be carried out with the lower limit adjusted to this, and degraded performance is liable to result. Consequently, circumferential homogenization of furnace top burden distribution and its control will be the big subjects to be investigated in future research.

\section{Conclusion}

The stability of burden trajectory into blast furnace top under intensive coal injection was reported from the viewpoints of burden distribution formation and falling trajectory control. The results of the work carried out allow us to draw the following conclusions.

(1) In the two-dimensional bell-less burden distribution test, the effect of ore falling trajectory on coke layer collapse was clarified. To cope with the rise of $\mathrm{O} / \mathrm{C}$, the control of ore falling trajectory is important from the viewpoint of preventing coke collapse when the ore base is increased in coke-based operation. In addition, when the coke base is lowered in ore-based operation, control of the coke falling trajectory becomes still more important from the viewpoint of deflection and dispersion of coke falling trajectory to the wall side.

(2) In the two-dimensional bell-less burden distribution test, the effect of burden particle size on the falling trajectory was clarified. Lowering the tilting angle of rotating chute in forming flat parts for ore and coke as a result of shifting to high $\mathrm{O} / \mathrm{C}$ operation increases the effect of burden particle size on the falling trajectory which serves as the operation disturbance factor, and promotes instability of control. Consequently, control of the falling trajectory becomes still more important in achieving stable burden distribution control under intensive coal injection.

(3) Since prediction of falling trajectory as mass flow is presently impossible, a falling trajectory measuring technique was developed utilizing acceleration sensors which can continuously measure the burden falling trajectory, in particular, main stream position and falling width. This technique has enabled the standard deviation distribution of acceleration signals to express the intensity distribution of the falling position, and the maximum value of the approximated curve of the standard deviation distribution can be assessed as the main stream position of mass flow which can be physically defined.

(4) In Kobe BF3 (3rd campaign) which is a bell-less top blast furnace under intensive coal injection, the falling trajectory measuring technique was applied. The effect of centrifugal force on the rotating chute can be detected by the deflection of standard deviation of acceleration signals to the wall side. Furthermore, the standard deviation distribution of acceleration signals can follow the falling trajectory which varies in time-series under the effect of discharge flux from furnace top hopper and particle size segregation in addition to the bell-less point, and the physical main stream position that is determined from the mass flux can be uniquely determined.

(5) For the shift to pellet operation as a result of shutdown of sintering plant in the end of May 1999 at Kobe BF3 (3rd campaign), deflection of ore falling trajectory to 
the furnace wall side due to swing-up of pellets in the rotating chute can be quantitatively assessed by the present falling trajectory measuring technique, contributing to the adoption of all pellet operation by correcting the circumferential balance by reducing the vertical chute diameter.

Furthermore, in order to pursue the reduction of molten iron cost while extending the blast furnace life, operation flexibility that can accommodate changes of material and fuel conditions as well as production rate becomes essential, and engineering understanding on further refinement of burden distribution control and stability of furnace condition must be deepened.

\section{REFERENCES}

1) S. Sakurai: Tetsu-to-Hagané, 68 (1982), 2319.

2) K. Narita, S. Inaba, I. Kobayashi, K. Okimoto, M. Shimizu, T.
Yabata and S. Tamada: Tetsu-to-Hagané, 65 (1979), 358

3) J. O'Hanlon: Iron Steel Eng., 68 (1991), December, 13.

4) N. Konno, H. Shioda, Y. Fujiwara, K. Araki, I. Hamada, H. Nagai and H. Sugiwara: CAMP-ISIJ, 6 (1993), 106.

5) Y. Kajiwara, T. Jimbo, T. Joko, Y. Aminaga and T. Inada: Tetsu-toHagané, 71 (1985), 175.

6) Y. Okuno, K. Kunitomo, T. Irita and S. Matsuzaki: Tetsu-to-Hagané, 72 (1986), 783

7) K. Takeda, Y. Konishi, S. Taguchi and T. Fukutake: Tetsu-to-Hagané, 73 (1987), 2084.

8) T. Matsuo, Y. Kanazuka, K. Hoshino, Y. Yoshida, S. Kitayama and S. Ishiwaki: Ironmaking Conf. Proc., ISS, Warrendale, PA, (1997), 203.

9) T. Naito: Industrial Measurement Handbook, Asakura Publishing Co., Ltd., Tokyo, (1976), 168.

10) Y. Matsui, A. Sato, T. Oyama, T. Matsuo, S. Kitayama and R. Ono: ISIJ Int., 43 (2003), 166.

11) S. Inaba, K. Okimoto, K. Nishida, T. Yabata and M. Takada: Kobe Steel Eng. Rep., 34 (1984), 42. 